\title{
DESAFIOS COTIDIANOS: EM BUSCA DE UMA ESCOLA INCLUSIVA
}

\author{
DAILY CHALLENGES: LOOKING FOR AN INCLUSIVE SCHOOL
}

\author{
Jhonathas Armond Assis Ramos ${ }^{1}$
}

\begin{abstract}
Resumo: Atualmente, muitas crianças, jovens e adolescentes com deficiência ainda estão fora da escola, o que revela que ainda não se tem uma educação inclusiva, de fato, no Brasil. Muito do que ocorre se passa por inclusão, mas trata-se de outro termo (integração), que não contempla o que a educação inclusiva objetiva. Neste trabalho, procurou-se abordar a diferença entre os termos "inclusão" e "integração", mostrando a realidade da luta pela educação inclusiva em nosso país, e observou-se mais atentamente, como via de exemplificação, como a prática pedagógica do educador pode se voltar para um estudante com deficiência visual. Como metodologia, utilizaram-se textos da literatura científica para dar suporte teórico ao tema em questão. Concluiu-se que, muito além da estrutura física, as escolas precisam se adequar em diferentes aspectos para promover uma educação que atenda coletivamente à particularidade apresentada por cada educando, seja ele com deficiência ou não.
\end{abstract}

Palavras-chave: Deficiência visual; educação inclusiva; inclusão.

\begin{abstract}
Currently, many children, youth and adolescents with disabilities are still out of school, which reveals that there is not yet an inclusive education, in fact, in Brazil. Much of what is happening is through inclusion, but it is another term (integration), which does not contemplate what inclusive education aims at. In this paper, we tried to address the difference between both terms "inclusion" and "integration", showing the reality of the struggle for inclusive education in our country, and observed more closely, as an example, as the educator's pedagogical practice may turn to a visually impaired student. As a methodology, texts of the scientific literature were used to give theoretical support to the subject in question. It was concluded that, far beyond the physical structure, schools need to adapt in different aspects to promote an education that collectively meets the particularity presented by each student, whether or not disabled.
\end{abstract}

Keywords: Visual impairment; inclusive education; inclusion.

\section{Introdução}

Infelizmente, milhares de crianças, adolescentes e jovens com deficiência, mesmo nos dias atuais, encontram-se fora da escola, à margem da sociedade. Isso ocorre principalmente porque nossa realidade revela que não temos ainda uma escola que seja, de fato, inclusiva, que respeita e valoriza cada particularidade de seus estudantes, sendo essa a mesma base para uma sociedade justa para todos, a qual deve se modificar, a fim de garantir os direitos de qualquer cidadão.

A educação inclusiva procede de muitas discussões e estudos provenientes da participação de pessoas com deficiência e educadores em todo o mundo, sendo resultante de um contexto histórico em que a educação é resgatada como lugar do exercício da cidadania e da garantia de direitos. Diversos foram os documentos produzidos sobre a deficiência e a educação inclusiva no Brasil e no mundo. Internacionalmente, a Declaração Universal dos Direitos Humanos, de 1948, estabelecida pela Organização das Nações Unidas (ONU), foi o primeiro desses documentos a perceber que as escolas feriam, muitas vezes, os direitos de vários sujeitos já marginalizados na sociedade. A partir da Declaração, diversos outros estudos e documentos foram criados, como a

\footnotetext{
${ }^{1}$ Universidade Federal de São João del-Rei, São João del-Rei, MG, Brasil.
} 
Declaração Mundial sobre Educação para Todos (Conferência de Jomtien), de 1990, a Declaração de Salamanca sobre Princípios, Política e Práticas na Área das Necessidades Educativas Especiais (1994), e a Convenção Interamericana para a Eliminação de Todas as Formas de Discriminação contra as Pessoas Portadoras de Deficiência (Convenção da Guatemala), de 1999, propondo uma escola que respeitasse as peculiaridades de cada estudante e oferecesse alternativas que atenderiam às suas necessidades educacionais. No Brasil, diversas leis orgânicas e constituições estaduais passaram a estabelecer o direito de estudantes com deficiência(s) na modalidade regular de ensino, de forma a garantir o atendimento específico por eles necessitado (GIL, 2005). São exemplos dessas políticas elaboradas pelo Estado brasileiro a Lei de Diretrizes e Bases da Educação Nacional, de 1996, as Estratégias para a Educação de Alunos com Necessidades Educacionais Especiais, de 2003, e a Lei Brasileira de Inclusão da Pessoa com Deficiência (Estatuto da Pessoa com Deficiência), de 2015.

Na educação inclusiva, portanto, a deficiência dos estudantes nada mais é do que uma das muitas características que cada educando possui, buscando, dessa maneira, respeitar as particularidades e descobrir formas diversas para educar e avaliar seus educandos com igualdade de direitos e eficácia. Como afirma Gil (2005), os benefícios desse modelo são sentidos não somente pelos estudantes com deficiência, mas por toda a escola, reduzindo a desistência e a repetência escolar, aumentando a autoestima e o aprendizado dos educandos e ajudando a construir uma sociedade mais justa, igualitária e respeitosa. Além disso, as famílias e a comunidade são fundamentais para o sucesso de uma escola inclusiva, a qual, ao ser consolidada, ainda é capaz de ajudar o professor a desenvolver diferentes estratégias que se adequem às necessidades de seus estudantes.

\section{Integração ou inclusão?}

Segundo Mantoan (2004), os vocábulos "integração" e "inclusão", apesar de possuírem significados semelhantes, são utilizados para designar situações distintas de inserção, baseandose em posicionamentos teórico-metodológicos que divergem entre si.

Os movimentos em favor da integração de crianças com deficiência surgiram nos países nórdicos em 1969, quando se questionaram as práticas sociais e escolares de segregação. Sua noção básica é o princípio de normalização. [...] O processo de integração ocorre dentro de uma estrutura educacional que oferece ao aluno a oportunidade de transitar no sistema escolar, da classe regular ao ensino especial, em todos os seus tipos de atendimento: escolas especiais, classes especiais em escolas comuns, ensino itinerante, salas de recursos, classes hospitalares, ensino domiciliar e outros. Trata-se de uma concepção de inserção parcial, porque o sistema prevê serviços educacionais segregados (MANTOAN, 2004, p. 39-40).

Portanto, o que se vê é que a integração é a inserção parcial e condicional dos estudantes com deficiência na escola regular, contentando-se com transformações superficiais, uma vez que as pessoas com deficiência devem se adaptar aos modelos que já existem na sociedade, a qual faz apenas ajustes em suas estruturas. Por essa perspectiva, há uma tendência a se disfarçar as limitações para aumentar as possibilidades de inserção.

Ações educativas inclusivas possuem como eixos "o convívio com as diferenças, a aprendizagem como experiência relacional, participativa, que produz sentido para o aluno", contemplando a subjetividade de cada um, embora seja um processo que se construa no coletivo das salas de aula (MANTOAN, 2004, p. 39). Nesse sentido, o termo "inclusão" questiona, assim 
como as políticas e a organização da educação especial e regular, o próprio conceito de integração. A inclusão prevê a inserção escolar de forma radical, completa e sistemática, em que todos os alunos, sem exceções, devem frequentar as salas de aula do ensino regular. Portanto, a inclusão é incompatível com a integração (MANTOAN, 2004).

A inclusão, por isso, exige rupturas nos sistemas, com o intuito de inserir total e incondicionalmente a todos os estudantes, de modo que a escola deve se adaptar para atender às necessidades tanto das pessoas com deficiência quanto dos demais indivíduos. Logo, a escola inclusiva valoriza a individualidade dos seus educandos.

\section{Deficiência visual na sala de aula}

Assim como cada indivíduo apresenta suas características únicas que o definem, os estudantes com deficiências também apresentam suas peculiaridades em sala de aula. Uma pessoa com deficiência visual, no contexto escolar, por exemplo, pode mostrar irritação constante nos olhos, aproximar muito o rosto do papel, apresentar dificuldade para copiar material da lousa a distância, franzir os olhos para ler o que está escrito na lousa, inclinar a cabeça para ler ou escrever, tropeçar frequentemente quando encontra por pequenos obstáculos no chão, ter dificuldade para enxergar em ambientes muito claros ou muito escuros (GIL, 2005).

Segundo Gil (2005), como professor, é possível tocar o braço do educando cego para que ele saiba que se está falando com ele, oferecer o cotovelo ou ombro para ajudar o educando a se locomover pelo espaço físico da escola, avisar e indicar quando houver modificação na posição dos móveis, encostar sempre as portas, ser preciso ao indicar direções, ler o que está escrito na lousa, procurar o professor especializado para acompanhar de perto o processo da aprendizagem do sistema braile pelo estudante, buscar recursos pedagógicos auxiliadores, disponibilizar, se possível, o material de estudo sob forma de textos ampliados, utilizar figuras para identificar os conteúdos, e sempre procurar ter o comportamento mais natural possível, sem superproteção ou sem ignorá-lo.

Para a autora, as potencialidades de um estudante com deficiência visual são as mesmas para um educando que pode enxergar sem dificuldade. Contudo, é preciso que o professor saiba adaptar as representações gráficas e os recursos didáticos que irá utilizar durante as aulas. Nesse processo de adaptação, todos os estudantes acabam por se beneficiar, pois utilizam-se materiais concretos, que facilitam a compreensão dos conceitos trabalhados (GIL, 2005).

\section{O papel da escola}

Diante de casos como o citado acima, uma escola inclusiva deve propor métodos de ensino-aprendizagem capazes de contribuir para a formação de todos os estudantes, pensando em suas peculiaridades, estando preparada para lidar com elas, e promover uma educação que se faça no conjunto dessa diversidade. Segundo Celedón (2005), o professor precisa se comprometer com seus educandos para que todos possam desenvolver suas habilidades individuais. Estimular, acreditar nos seus estudantes e em suas capacidades, dar o suporte necessário, repensar os sistemas de avaliação dos processos educativos, estimular a participação dos pais e dos outros professores, e trabalhar com um currículo flexível são atitudes que podem e devem ser pensadas e planejadas para a inclusão escolar (CELEDÓN, 2005).

Trabalhar a interdisciplinaridade em sala de aula pode contribuir muito para a aprendizagem e a formação dos estudantes. Como afirma Mantoan (2004, p. 38):

A exclusão escolar manifesta-se das mais diversas e perversas maneiras, e quase sempre está em jogo a ignorância do aluno, diante dos padrões de 
cientificidade do saber escolar. [...] O pensamento subdividido em áreas específicas é uma grande barreira para os que pretendem, como nós, inovar a escola. Nesse sentido, é imprescindível questionar esse modelo de compreensão que nos é imposto desde os primeiros passos de nossa formação escolar e que prossegue nos níveis de ensino mais graduados. Toda a trajetória escolar precisa ser repensada, considerando-se os efeitos cada vez mais nefastos das hiperespecializações dos saberes, que nos dificultam a articulação de uns com os outros e, igualmente, uma visão do essencial e do global.

Ainda de acordo com a autora acima citada, em vez de reconhecer as inter-relações entre os distintos conhecimentos escolares, o que se faz é isolar, separar esses mesmos conhecimentos. Aprende-se muito mais pela recomposição, contextualização e integração dos saberes, conectados em redes de entendimento, não reduzidos ao simples, compreendendo o caráter multidimensional dos problemas da realidade, e nos tornando mais capazes de propormos as soluções cabíveis (MANTOAN, 2004).

\section{Conclusão}

Há muito o que ser feito para que se tenha realmente uma escola inclusiva, aquela que acolhe e aceita cada estudante com suas particularidades, desenvolvendo as formas e estratégias pedagógicas necessárias para lidar eficazmente com as peculiaridades de seus educandos. Trata-se de mudanças na estrutura física, mas, principalmente, de mudanças na mentalidade, para a quebra de preconceitos diante da diversidade de que nossa sociedade é composta. Além de promovermos a inclusão dessa margem da sociedade, estaremos também realizando transformações que ultrapassam as fronteiras escolares, desenvolvendo ações que, ao longo do tempo, resultarão em uma sociedade que convive bem e respeita as diferenças humanas.

Para uma educação que seja, de fato, inclusiva, é preciso que todas as crianças tenham as mesmas oportunidades de acesso, permanência e aproveitamento escolar, independentemente de suas características particulares, o que dispõe, antes, de condições de acesso físico e equipamentos adequados, além de profissionais preparados. É preciso entender também que o fracasso escolar é uma falha que envolve a escola, a comunidade e a família dos estudantes à medida em que estas não conseguem atender às suas necessidades, pois a deficiência nada mais é do que as dificuldades que a pessoa com deficiência(s) enfrenta diante de um ambiente (digase sociedade) despreparado para recebê-la.

\section{Referências}

CELEDÓN, Esteban Reyes. Inclusão escolar: um desafio. Esteban Reyes Celedón, Lisboa, set., 2005. Disponível em: http://www.geocities.ws/profestebanpolanco/inclusao.htm. Acesso em: 15 maio 2018.

GIL, Marta (Coord.). Educação Inclusiva: o que o professor tem a ver com isso? São Paulo: Imprensa Oficial do Estado de São Paulo, 2005.

MANTOAN, Maria Teresa Eglér. O direito de ser, sendo diferente, na escola. $R$. $C E J$, Brasília, n. 26, p. 36-44, jul./set. 2004. 


\section{Sobre o autor}

Jhonathas Armond Assis Ramos. Graduado em Licenciatura em Ciências Biológicas (Instituto Federal de Educação, Ciência e Tecnologia do Sudeste de Minas Gerais) e em Licenciatura em Pedagogia (Centro Universitário Internacional), e tem Mestrado em Educação: Processos Socioeducativos e Práticas Escolares (Universidade Federal de São João del-Rei). Tem experiência na área da Educação, mais especificamente em Sociologia da Educação, com pesquisas nos seguintes temas: desigualdades escolares, internacionalização dos estudos, trajetórias e estratégias de escolarização. Foi bolsista da Universidade Federal de São João del-Rei.

E-mail: jhonathas.armond@gmail.com. 